\title{
The Effectiveness of the Use of Information and Communication Technology (ICT) in Rural Secondary Schools in Malaysia
}

\author{
Idarwana Hasin ${ }^{1}$ \\ M. Khalid M. Nasir ${ }^{2 \rtimes ~(D) ~}$ \\ ${ }^{1,2}$ Faculty of Education, Universiti Kebangsaan Malaysia (UKM), Malaysia \\ Email:idarwana80@gmail.com Tel: +60145224529 \\ Email:mdkhalid@ukm.edu.my Tel:+601115154449
}

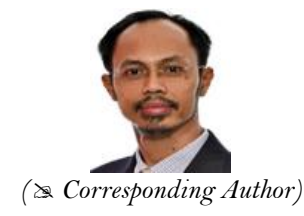

Abstract

The Ministry of Education has established viable educational ecosystems in order to ensure the equality of rural education. There are three aspects that have been outlined, namely value-based education, quality improvement, and autonomy and accountability of schools and universities. Hence, a study in the form of a survey was conducted to identify the issues surrounding information technology faced by students and teachers in rural secondary schools, and to provide an overview of the usage of Information and Communication Technology (ICT) as well as students' knowledge and teachers' skills in the teaching and learning process. A total of 49 respondents were involved, comprising 21 students and 28 teachers from nine secondary schools located in one rural area of Kelantan. The findings revealed that a majority of the respondents perceived the use of ICT positively, despite the lack of facilities and expertise. Thus, a need for relevant ICT training was raised by the teachers. Recommendations are also discussed to guide the authorities in planning and preparing appropriate equipment and facilities for the schools, as well as adequate training for teachers and facilitators, before a new policy is introduced to the students. Further research is also recommended to examine the rural students' acceptance of the use of technology.

Keywords: Information, Communication, Technology, Interest, Rural, Secondary school

Citation | Idarwana Hasin; M. Khalid M. Nasir (2021). The Effectiveness of the Use of Information and Communication Technology (ICT) in Rural Secondary Schools in Malaysia. Journal of Education and e-Learning Research, 8(1): 59-64. History:

Received: 27 October 2020

Revised: 30 November 2020

Accepted: 22 December 2020

Published: 14 January 2021

Licensed: This work is licensed under a Creative Commons Attribution 3.0 License $(\mathrm{cc})$

Publisher: Asian Online Journal Publishing Group
Acknowledgement: Both authors contributed to the conception and design of the study.

Funding: This study received no specific financial support

Competing Interests: The authors declare that they have no conflict of interests.

Transparency: The authors confirm that the manuscript is an honest, accurate, and transparent account of the study was reported; that no vital features of the study have been omitted; and that any discrepancies from the study as planned have been explained.

Ethical: This study follows all ethical practices during writing.

\section{Contents}

1. Introduction

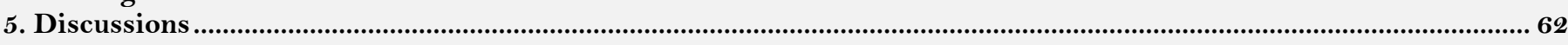

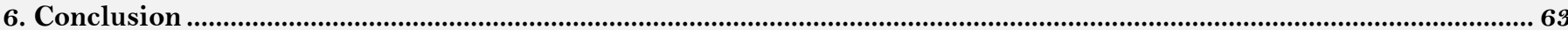




\section{Contribution of this paper to the literature}

This paper provides guidelines readers and the authorities in planning and preparing appropriate equipment and facilities for the schools, as well as adequate training for teachers and facilitators.

\section{Introduction}

Based on educational issues such as imbalance and lack of technology in education, especially in rural areas, the Ministry of Education (MOE) envisions narrowing the educational gap between urban and rural students by providing equal privileges and facilities. Rural education studies are studies conducted to improve the quality of teaching and learning in rural areas, as well as to ensure that the students' achievement in both areas, urban and rural, are on par without much significant difference. Rural schools are defined as schools that are located in rural areas, such as villages, and these places are commonly considered to be left behind in terms of technology, infrastructure, quality of life, and so on. According to Andin, Ambotang, Kamin, and Hamzah (2019), rural schools are often associated with obstacles to education due to the lack of various basic facilities, as compared to schools in the city. However, this insufficiency does not correlate with the students in rural schools performing poorly academically. It should be emphasized that rural learning is not outdated. The school infrastructure should be improved and equipped with computers. As concluded by Nidzam, Ahmad., Nidzam., Shaharim, and Yahaya (2016), a comfortable atmosphere in school is crucial to the students and teachers establishing an effective teaching and learning environment, as students spend almost half of their day in school. Therefore, teachers need to be more creative and innovative in implementing lessons, so that students can acquire knowledge and engage in learning. Education today is the conscious mastery of information technology among school students (Ab Rahman, Zainal, \& Ab Karim, 2015).

The education system in Malaysia is booming. In this era of increasingly extensive ICT, its role in the teaching and learning process in schools has garnered attention. Various teaching methods have been introduced in order to have a significant impact on trainers to educate students in rural areas in acquiring knowledge. The MOE has proposed several policies and initiatives to advance education by integrating ICT programs in teaching and learning. The use of ICT in teaching and learning refers to the use of ICT in an orderly and appropriate manner to enhance the efficiency of the process and the effectiveness of teaching and learning. Agreeing with Andin et al. (2019), the use of ICT in schools changes the methods of teaching and learning for rural education. Generally, this study proves that students quickly learn how to use the facilities and develop relevant ICT skills. In the context of education, ICT can assist in management and administrative tasks and act as a tool to facilitate the teaching and learning environment across all subjects.

The major urban education issue, in terms of information technology, is the difficulty of providing equal facilities to rural and urban students. Mohamed, Gambling, Zawiyah, and Yusof (2012) acknowledge that access to telecommunications technology, including internet connections, is another factor which contributes to the gap between rural and urban students. ICT facilities are often associated with students' activities in communicating or carrying out their tasks digitally. Timbang and Ambotang (2020) agree that, as ICT is the acronym of Information and Communication Technology, the technology required for data processing is related to all aspects of information management and processing. Computers and software can be used to change, store, protect, process, transfer, view, and obtain information accurately and easily, regardless of location and time.

The purpose of this study is to provide an overview of the ICT facilities available in rural secondary schools in the Gua Musang district, the current knowledge and skills of teachers in the field of ICT, as well as the problems or issues faced by teachers and students in using ICT for the teaching and learning process. The findings of the study could assist the MOE and relevant stakeholders in understanding the obstacles and challenges with regards the use of ICT in rural schools and formulating appropriate programs to address the needs of ICT facilities and the capability of secondary school teachers in rural areas in implementing ICT in teaching and learning.

\section{Literature Review}

In this era of globalization, the MOE has been upgrading the quality of education in order to ensure that the academic achievement of rural and urban areas is on par. Nevertheless, education in rural areas is still lagging behind due to a lack of facilities, significant community education gaps, low academic achievement, a lack of teaching aids, as well as a lack of information technology facilities (Raman, Othman, \& Affandi, 2019). According to Belalang and Abd Rahman (2016) the knowledge and skills necessary to understand ICT include hardware, software, the network system of the local area network, the Internet, and other components of technology and communication. The use of ICT in the teaching and learning process could improve the efficiency and effectiveness of the learning outcomes (Nasir, Surat, Maat, Abd Karim, \& Daud, 2018a; Sufian, Nordin, Tauji, \& Nasir, 2020). According to Silin and Kwok (2017), effective use of ICT in teaching and learning could strongly influence students and teachers to implement ICT in rural school learning. Teachers could make early preparations prior to the lesson by seeking appropriate teaching materials, as well as engaging teaching methods, in order to ensure that the lesson could be delivered effectively. They could also transform the learning process through the use of tools like PowerPoint and other interactive visual aids. The use of ICT is important for teachers to share knowledge and develop themselves in the field of education (Khan, 2017).

However, there are also hindrances to rural ICT facilities. Some schools do not have adequate technology infrastructure and support materials to underpin the teaching and learning process in the classroom. Time constraints are another obstacle which restrains the use of ICT in the teaching and learning process. Moreover, students are not able to use the Internet due to a lack of necessary equipment, such as laptops and desktops, as well as unstable internet speeds, as the internet services are limited. In addition, as claimed by Raman et al. (2019) this issue arises as a result of trainers in the field who are unskilled in ICT. This is because trainers are lacking in experience and knowledge in terms of ICT. In addition, instructors could easily clarify complex instructions (Khalid \& Quick, 2016; Nasir., Mansor, \& Rahman, 2018b). They could conduct interactive sessions by making the lessons better, and eventually increase the concentration of students (Timbang \& Ambotang, 2020). According to 
Herbert, Campbell, and Loong (2016) rural schools may also face challenges accessing online resources, as they depend on the expertise of their teachers and the availability of technology facilities.

ICT facilities could address the needs of individual learning styles, including auditory, visual, kinesthetic and verbal. Educators use information technology to help them prepare instruction materials, so that teaching and learning can be more exiting (Min \& Nasir, 2020). The national education level is good and competitive with the outside world (Raman et al., 2019). The MOE is in the process of equipping schools with adequate ICT facilities in order to ensure that the students can compete globally in the field of technology. The ministry has diversified strategies and technology facilities provided for rural teachers, in order that they are able to access and use technology facilities equally on par with urban schools (Kelly et al., 2018). Among the strategies used to enhance the technology is the development of ICT facilities and an increase in the number of IT experts and experienced teachers in rural schools.

\section{Methodology}

This research study is in the form of a survey using questionnaires. Survey research is a quantitative method. A set of questionnaires is provided and distributed to the respondents in order to obtain information. According to Raman et al. (2019) this method is suitable to gauge the views of the respondent on an issue or topic, achievement of an objective, and attitude and behaviour of the respondents. This survey study is designed in accordance with quantitative research procedures. The survey method is suitable due to its high reliability and the low cost of implementation. The questionnaires, which are in descriptive form, are distributed to teachers and students for data analysis.

The instrument, which is a set of questionnaires, is used as a measuring tool to collect the required data and consists of two parts, Part A and Part B. Part A consists of demographic information of the respondent. In Part B, the items concern the level of ICT usage in school, the impact of ICT in schools, and recommendations to increase the use of ICT in rural areas. Respondents are required to indicate whether they agree or disagree with each item and answer open-ended questions. Prior to the data collection, researchers first referred the questionnaire to an expert for a review of the formulation of questions and title correction. After the questions were established, researchers distributed the questionnaire via online Google Form. The researchers also offered assistance to some respondents who faced difficulties in answering the questionnaire. The data obtained were then analyzed quantitatively.

Forty-nine respondents, comprising 21 students and 28 teachers from nine secondary schools in the Gua Musang district of Kelantan were involved in this study. This location was chosen as research on ICT in rural education had yet to be carried out in this area. This indirectly created a gap in the research, and a need for the researchers to study ICT at the secondary school level in the district. In addition, this location was closer and it saved time for researchers to conduct studies on all the secondary schools in the Gua Musang district. Apart from that, researchers could shorten the research time as the schools involved are located closer together, hence are easier to visit as compared to other districts. In this study, a random sampling method was applied. Researchers distributed the set of questions randomly to teachers and students.

\section{Findings}

Of the respondents, $42.9 \%$ were teachers and $57.1 \%$ were students as presented in the analysis of the respondents' demographic information in Table 1.

Table-1. Respondents' profile according to job status.

\begin{tabular}{c|c|c|c}
\hline Demographic & Respondent categories & Frequency & Percentage\% \\
\hline Job Status & Teacher & 21 & $42.9 \%$ \\
\hline & Student & 28 & $57.1 \%$ \\
\hline
\end{tabular}

The analysis of the difficulty in accessing ICT learning shows that $96 \%$ of respondents agreed that rural students had difficulty in learning due to the lack of facilities and experts. As schools are located in remote areas, they were unable to utilize ICT for teaching and learning purposes due to the limited access to ICT. According to Ishak and Rusman (2018) insufficient physical facilities and inadequate teaching aids could lead to a failure to achieve the learning objectives, especially in terms of the success of the students as presented in Table 2.

Table-2. Opinions on difficulty in accessing ICT learning for rural students.
\begin{tabular}{c|c|c}
\hline Item & Number & Percentage\% \\
\hline Opinion & & \\
\hline Agree & 47 & $96 \%$ \\
\hline Disagree & 2 & $4 \%$ \\
\hline
\end{tabular}

The analysis shows that $98 \%$ of respondents agreed that rural residents require technology facilities. The respondents also agreed that rural residents should have access to technology and infrastructure facilities in the school so that students could compete with urban students, as well as gain appropriate knowledge and skills in technology and communication as presented in Table 3.

\begin{tabular}{c|c|c} 
Table-3. The reasonableness of information and communication technology facilities for rural students. \\
\hline Item & Number & Percentage\% \\
\hline Fairness & & $98 \%$ \\
\hline Reasonable & 48 & $2 \%$ \\
\hline Unnatural & 1 &
\end{tabular}


The analysis shows that rural education has issues with technology facilities. There are some schools that do not have adequate technology infrastructure and support materials to assist the teaching and learning process, especially computers and computer laboratory facilities. Time constraints and inadequate facilities have also been a barrier to the use of ICT in the teaching and learning process. For example, students were not able to use the Internet due to a lack of equipment such as laptops and desktops, the internet services are limited, and the internet network is not easily accessible. In addition, this issue arises as a result of trainers who are unskilled in the field of ICT, as they lack in experience and knowledge of ICT. In addition, inexperienced teachers in terms of ICT literacy are sent to rural schools. This will cause students to get less exposure, lowering their confidence and passion to learn, as teachers do not apply the technology in teaching and learning in schools. Meanwhile, according to Shanmugam and Balakrishnan (2019) the lack of the use of ICT in rural schools results in rural students being unable to keep abreast of these subjects more efficiently and prevents them from performing well in the subjects taken.

From the outcome of the study, most of the respondents agreed that the ICT facilities are not sufficient for the school community, especially students. The lack of technological facilities could result in students being left out in their learning. This is because computer-based lessons could not be carried out effectively due to the difficulties in finding information online. Hence, students will not be interested to learn because they are bored because of the incomplete technology facilities and infrastructure.

In addition, there are gaps of equality and education between rural and urban schools in producing technologysavvy students. This is because the constraints and lack of ICT facilities will affect the effectiveness and the quality of rural education. This is because the services to access the Internet are limited and the performance of the trainers differs due to a lack of experience and knowledge. As shown in this study, $87.5 \%$ of the respondents agreed that there is a knowledge gap and competition between rural and urban students due to the impact of the use ICT in rural education as presented in Table 4.

\begin{tabular}{c|c|c}
\multicolumn{2}{c}{ Table-4. Differences in achievement level between rural and urban students. } \\
\hline Item & Number & Percentage\% \\
\hline Opinion & & \\
\hline Agree & 42 & $85.70 \%$ \\
\hline Disagree & 7 & $14.30 \%$ \\
\hline
\end{tabular}

In addition, rural students are not interested in learning due to the unfamiliarity of ICT jargon and terminology such as tablet and e-learning portal. This is due to the geographic factor, where the school area is located in isolated areas. As a result, these schools have high student drop-out rates. This will leave a negative impact on the students in terms of the learning process. Therefore, the authorities will need to provide a conducive place and make the necessary facilities available to students in rural areas.

As a result of this study, respondents outlined ways to overcome the problems faced by schools in rural areas. One possibility is that the MOE could plan and conduct relevant workshops and training programs, such as basic training in computer usage and information technology. In addition, computer usage training should be provided to teachers and students in order to enhance the students' capabilities and interests to master the appropriate ICT knowledge and skills. As a result, the students would be able to acquire the knowledge of information technology and thus attract more students to study and be able to develop their teaching and learning processes. If this workshop or training were implemented, it would be more focused on teachers in rural areas, and ICT gaps could be closed between the cities and rural areas.

In addition, the Government needs to improve the facilities in rural schools by providing more electronic equipment such as computers, LCD projectors and computer laboratories in order to expose and familiarize the students and teachers to implementing ICT in the teaching and learning process. Thus, students' academic achievement would be improved thus producing students who are skilled and knowledgeable in information technology. The government and the Malaysian MOE have given the 1 Malaysia notebook for free to eligible students in urban and rural schools. It has helped students from low-income families to have their own computer to perform tasks. Guidance from teachers is crucial in order to ensure that students use ICT in a proper and prudent manner.

Furthermore, the Government needs to improve the wireless connection facility services in rural schools. Consequently, teachers would be able to access the Internet in planning and creating more attractive and effective materials for students during the teaching and learning process in the classroom. They would be able to access the Internet quickly and easily and students would feel comfortable and interested in the lesson. For example, in terms of convenience, the Internet speed needs to be improved so that students can find materials and use ICT. Therefore, sufficient facilities will lead to the active participation of rural students in lessons regarding the use of the ICT facilities. In addition, the Government needs to put an emphasis on ICT subjects to students by improving the content and the learning materials. This knowledge is very important for students as they could apply the knowledge in the outside world and in their daily lives for a long period of time, even at the university or employment level.

\section{Discussion}

Based on the analysis, the results show that the ICT facilities at secondary schools in rural areas are less satisfying and unresponsive, as compared to secondary schools in the city. The results show that learning and teaching using ICT in rural secondary schools clearly differed from schools in the city, as teachers integrate ICT merely as a teaching aid. In addition, the use of ICT is more attractive to lower secondary students as compared to upper secondary students. Normally, teachers will use the LCD projector and laptops provided by the Malaysian MOE or the district Education Office in the classroom. They also use various types of teaching approaches, including the use of Power Point. They use colored graphics and images in order to keep students from sleeping and playing in class. Nevertheless, the textbook remains the main guide. 
Furthermore, the most visible factor in the lack of infrastructure in rural secondary schools is the lack of computers, LCD projectors, laptops, tablets, and online systems. The rural schools do not have sufficient infrastructure facilities. As the location of these schools is rural, the difficulty of accessing the Internet is undeniable. Hence, it is difficult to find teaching materials quickly and effectively. However, the schools have made great efforts to upgrade the Internet usage and ICT facilities from time to time, despite the high capital and cost for the maintenance process. According to Gosal (2018) complete infrastructure facilities can help students to learn. For rural schools with dormitories, adequate infrastructure facilities are very important. This ensures the comfort of rural students. However, there are some schools that do not have sufficient basic equipment such as a resource center, football field, computer laboratories and so on.

Furthermore, the teachers also complain about an insufficient period of teaching for the subject of ICT. This time constraint is usually faced by teachers who are able to use e-Learning, such as science teachers in laboratories. Teachers also need to share an LCD projector even need to make reservations a week in advance to use the ICT equipment. Apart from that, rural areas, for the most part in Gua Musang, do not have internet coverage. This causes students from this area to have difficulty in accessing the Internet. Internet usage does not necessarily affect the learning sessions, but the use of the Internet is very important for students' self-learning (Min \& Nasir, 2020). For example, to find job information, additional information, training, and so on. The dependency on the Internet among students is a requirement, but the absence of internet coverage creates a gap between rural students and students in urban areas.

Additionally, each school has a computer lab facility. However, not all computers are connected to the Internet even though ICT has become a compulsory subject for all students. This has been a nuisance and a challenge to the teachers because they need the Internet to send information and key-in scores directly into the web for them to reach the MOE and the district Education Office. Meanwhile, for the students, the use of the Internet is always dependent on the school. The use of ICT is very helpful in facilitating teaching and learning for both teachers and students in the classroom (Intarat, Chanchalor, \& Murphy, 2017).

In strengthening the use of ICT, skill in using computers is essential. Besides students, there are also teachers who still do not know how to use a computer or access information over the Internet. Based on experience, these teachers have experience in teaching but are less skilled in using current technologies. If the teacher himself is less skilled, how can he teach and guide students in using and accessing information through ICT? This causes students to gain no benefit from the facilities of technology. Teachers need to innovate their teaching approaches. According to Raman et al. (2019) teachers and pupils are the main users for any technological innovation in education and the role of teachers is to ensure that students can utilize the ICT facilities even though they are in rural schools.

Lack of professional teachers has resulted in a very significant difference between rural schools and urban schools. This is because most professional teachers are not willing to be placed in rural areas. This has resulted in a lack of skilled teachers in rural areas that would cause ICT to be familiar to rural students. Apart from that, the problem of the lack of professional teachers is also due to the incomplete infrastructure, especially in the rural areas. Lack of ICT materials make the teacher less skilled in the use of ICT and unable to display it in class. The question is how likely teachers and students would be to use ICT if the material is not sufficient. In addition, teachers are not able to carry out ICT-based teaching approaches if the facilities and teaching materials are incomplete. According to Batane and Ngwako (2017) all teachers need to develop ICT skills to facilitate learning and strengthen pedagogy as well as expand educational knowledge, especially to students who have difficulty accessing technological facilities.

The lack of professional trainers is also due to the lack of attention given by the MOE to providing appropriate training to teachers in the use of ICT. Rural teachers are not strongly encouraged to be involved in ICT workshops. If a workshop is carried out, it tends to be more focused on teachers in urban areas than rural areas. Eventually, teachers in urban areas become more skilled while teachers in rural areas become outdated and backward in terms of the use of ICT. Ultimately, this causes students to be unable to enjoy the ICT facilities.

The MOE can use this finding as a guideline to provide better infrastructure to secondary schools in rural areas and implement ICT-related courses for teachers in schools - especially teachers in rural schools. In addition, this study hopes to assist the program-planning to provide appropriate materials for teachers and students, based on the level of ICT facilities at their respective schools. This is because a conducive environment causes students to be comfortable in school. According to Nidzam et al. (2016) a comfortable atmosphere in school is crucial to students and teachers in order to ensure effective learning and teaching. The use of ICT can facilitate pedagogy and improve student learning in the classroom but there are teachers who do not use ICT in their teaching to students, especially in rural areas (Heitink, Voogt, Fisser, Verplanken, \& Van Braak, 2017).

The Government's awareness of the importance of ICT has led to investments in ICT in primary schools, especially in rural areas. This is because the 4M skills - reading, writing, counting, and reasoning - are required for students to compete in this new millennium. According to Jamian (2016) the Government and MOE have initiated various efforts and forms of assistance that should become the catalyst and encouragement for teachers and schools to continue to help needy students. A person is considered computer literate when he has a basic understanding of computer functions, can use a computer to facilitate the implementation of daily tasks, whether for personal use or to work efficiently and effectively, and can interact with computers using applications such as multimedia and the Internet. Hence, it is hoped that the authorities will immediately take action to improve the level of ICT facilities in rural secondary schools.

\section{Conclusion}

In conclusion, the use of ICT among students in rural areas is crucial in order to produce students who are capable and knowledgeable in the field of ICT. Today's education demands that teachers and students equip themselves with knowledge and technological skills because the use of ICT has become a trend in this century.

The use of ICT in education can increase the learning potential of a student, especially in rural schools. This is because the use of technology is able to improve students' understanding of certain ICT concepts. Therefore, teachers should equip themselves with the knowledge associated with ICT. This is because technology has 
enhanced teachers' ability to carry out lessons, as they are able to use ICT in their teaching, as well as to guide students in mastering the highest level of knowledge.

Rapid development in the field of information technology should be fully utilized to produce a wise and knowledgeable generation who will administer the country in the future. It is the responsibility of the educational institution to educate the community to be aware of the importance of ICT literacy that can truly govern the country well in the future. As such, basic ICT literacy or skills should be implemented in the early stages of the child's development. The use of computer and information technology in teaching and learning systems is necessary to attract the interest of these students to continue to gain knowledge regardless of boundaries and barriers that may prevent them from learning.

The use of ICT as a communication tool has many benefits in terms of information and communication sharing. Teachers can take advantage of these capabilities to conduct collaborative learning lessons in class. This method is used to enable students and teachers from different locations to send, receive and share information in various forms of multimedia elements such as text, graphics, audio, video, and animation. The ICT component of teaching and learning is important and requires support and hard work from school leaders, teachers, students, and all parties. The integration of multimedia and Internet technologies could transform and elevate conventional teaching and learning methods. Through the use of this modern technology, students will be able to master their studies by using learning approaches and strategies that they are interested in, and will be able to bridge the academic gap between urban and rural students. They can also strengthen their knowledge of communication technology.

\section{References}

Ab Rahman, H., Zainal, N., \& Ab Karim, N. A. (2015). Effectiveness of the Use of ICT in the Teaching and Learning of Islamic Education for Sekolah Kebangsaan Desa Pandan Kuala Lumpur [Paper Presentation]. Paper presented at the E-Proceeding of the International Conference on Information Technology \& Society 2015. The Impact of Information Technology to the Society. Kuala Lumpur, Malaysia.

Andin, C., Ambotang, A. S., Kamin, Y., \& Hamzah, R. (2019). Transformation of the school environment through consensus of schools and rural communities. Geografia-Malaysian Journal of Society and Space, 15(2), 84-101.

Batane, T., \& Ngwako, A. (2017). Technology use by pre-service teachers during teaching practice: Are new teachers embracing technology right away in their first teaching experience? Australasian Journal of Educational Technology, 33(1), 48-61.

Belalang, W. N. A., \& Abd Rahman, M. J. B. (2016). Ict Literacy skills among Iban students In Rural Sibu, Sarawak. Issues and challenges. Paper presented at the In Proceeding 7 th International Seminar on Regional Education.

Gosal, R. (2018). Public perception of facilities andinfrastructure quality at school as one facilities on sindue district, donggala regency Asian Journal of Environment, History and Heritage, 2(2), $217-222$.

Heitink, M., Voogt, J., Fisser, P., Verplanken, L., \& Van Braak, J. (2017). Eliciting teachers' technological pedagogical knowledge. Australasian Journal of Educational Technology, 33(3), 96-109.

Herbert, S., Campbell, C., \& Loong, E. (2016). Online professional learning for rural teachers of mathematics and science. Australasian Journal of Educational Technology, 32(2), 99-114

Intarat, S., Chanchalor, S., \& Murphy, E. (2017). ICTs for non-formal education in rural Thailand. Australasian Journal of Educational Technology, 33(3), 107-121.

Ishak, R., \& Rusman, S. N. F. (2018). Teacher work performance and its relationship to workload factors, work environment and personal: A Case Study in a School in Sabah. Jupidi: Journal of Educational Leadership, 5(1), 1-15.

Jamian, A. R. (2016). The problems reading and writing skills Malay primary school pupils in rural areas. Malay Education Journal, 1(1), 1-12.

Kelly, N., Russell, N., Kickbusch, S., Barros, A., Dawes, L., \& Rasmussen, R. (2018). Online communities of teachers to support situational knowledge: A design-based study. Australasian Journal of Educational Technology, 34(5), 150-166.

Khalid, N. M., \& Quick, D. (2016). Teaching presence influencing online students' course satisfaction at an institution of higher education. International Education Studies, 9(3), 62-70.

Khan, A. (2017). Blog-based professional development of English teachers in Mumbai: The potential of innovative practice under scrutiny. Australasian Journal of Educational Technology, 33(34), 88-106.

Min, H., \& Nasir, M. K. M. (2020). Self-regulated learning in a massive open online course: A review of literature. European Journal of Interactive Multimedia and Education, 1(2), 1-6.

Mohamed, H., Gambling, H. M., Zawiyah, S. F. M. N., \& Yusof, M. (2012). The digital divide and rural education: Levels of information and communication technology in student literacy. Asia-Pacific Journal of Information Technology and Multimedia, 1(2), 1-13.

Nasir, M. K. M., Surat, S., Maat, S. M., Abd Karim, A., \& Daud, M. Y. (2018a). Confirmatory factor analysis on the sub-construct of teaching presence's in the community of inquiry. Creative Education, 9(14), 2245-2253.

Nasir., M. K. N., Mansor, A. Z., \& Rahman, M. J. A. (2018b). Measuring Malaysian online university student social presence in online course offered. Journal of Advanced Research in Dynamical and Control Systems, 10(12), $1442-1446$.

Nidzam, C., Ahmad., C., Nidzam., C., Shaharim, S., \& Yahaya, A. (2016). Environmental suitability learning, teacher-student interaction, learning commitment and learning comfort among students biology. Malaysian Journal of Science and Mathematics Education, 6(1), $101-120$.

Raman, K., Othman, N., \& Affandi, H. M. (2019). Information communication and technology (ICT) usage gaps between urban and rural schools. Malaysian Journal of Education, 44(1SI), 109-119.

Shanmugam, K., \& Balakrishnan, B. (2019). Designing an ICT guiding framework for science teachers in rural Tamil schools in Perak. Muallim Journal of Social Sciences and Humanities, 3(4), 441-458.

Silin, Y., \& Kwok, D. (2017). A study of students' attitudes towards using ICT in a social constructivist environment. Australasian Journal of Educational Technology, 33(5), 50-62.

Sufian, S. A., Nordin, N. A., Tauji, S. S. N., \& Nasir, M. K. M. (2020). The impact of covid-19 on the Malaysian education system. International Journal of Academic Research in Progressive Education \& Development, 9(2), 764-774.

Timbang, M., \& Ambotang, A. S. (2020). The influence of technological innovation, the role of administrators and the readiness of teachers on the professionalism of rural school teaching in sabah. Malaysian Journal of Social Sciences and Humanities (MJSSH), 5(2), 96-106. 